\title{
A transition research perspective on governance for sustainability
}

\begin{abstract}
In this paper we present the transition approach as an integrated perspective to understand and possibly orient our society towards sustainable development. Transition management is based upon complex adaptive system thinking and seeks to deal with ongoing changes in society in an evolutionary manner so as to influence these ongoing changes in terms of speed and direction: towards sustainability. Since the concept of sustainability is inherently normative, subjective and ambiguous, we argue that (unlike some more traditional approaches to sustainable development) we should focus on an open facilitation and stimulation of social processes towards sustainability. Transition perspective poses novel challenges for research: there are no unequivocal answers, nor is it clear how these processes should be governed. We thus end this paper by formulating the basic research questions central to the search for governance for sustainability.
\end{abstract}

\section{Introduction}

Over the last decade, sustainable development has become a central concept guiding scientific debates and policies related to complex and persistent problems (Jansen, 2003; Meadowcroft, 2000; Scott and Gough, 2004). Sustainable development aims to ensure economic welfare, social equality and ecologic quality across society, generations and into the future. It is commonly associated with those types of social problems that demand a fundamental restructuring of dominant paradigms, institutions and practices. In such a context, conventional forms of planning and policy but also traditional conceptions of knowledge and the role of scientists are being challenged (Bolin, 2000; Flyvbjerg, 2001; Kates et al., 2001). Over the last decade, new research and policy fields have emerged adopting more integrated perspectives and concepts, such as transition and resilience approaches that are explicitly based on complexity and uncertainty. In the transition perspective, our society is composed of complex adaptive systems in which individuals and organizations self-organize within the limits set by physical, institutional and informal structures, leading to the emergence of novel structures.

The transitions approach distinguishes different phases of change as result of the interaction between changes at different levels. For example the fundamental changes that are now required in our fossil energy supply, our ill-adapted water management, our individual and fossil based industry or our waste-production and management. Historical transitions such as energy supply or mobility transitions were semi-autonomous societal processes; since the vast majority was not steered in a collective way but emerged as a societal outcome. In our current era, the need to deal with immanent transitions so that they lead to more sustainable directions and explorations into the possibility of deliberative steering (or deliberate power streaming) of such societal processes yielded a new process-oriented approach, the transition management approach.

Transitions can take decades to materialize and are highly uncertain in terms of future development, possibilities for change and the level of intervention possible in such dynamic processes. Though it is clear that ongoing processes of change need to be oriented towards more sustainable system's states, the often blurred vision of what exactly is sustainable makes the pathways towards a sustainable system state highly uncertain. In this complex context, not only the translation of sustainability in a specific context needs to be coordinated with the sustainability values, but also actors involved need to re-evaluate their roles and practices (Loorbach, 2007). We argue in this paper that transition research offers a new approach to seek

Paper for: Sustainable Development: A challenge for European research 
understanding of sustainability transitions in society as well as to derive a mode of governance ${ }^{1}$ that takes into account the multi-faceted nature of sustainability and the co-evolutionary processes of societal transitions.

In our effort to present what transitions thinking can offer to sustainable development research, we first elaborate on existing propositions of sustainability and sustainable development (section 2). Sustainability research gave rise to a number of research streams among them transitions' research (Section 3). Transitions' approach takes into account the intrinsic characteristics of the societal system (e.g. complexity, interdependence, actor-networks) and perceives continuous structural changes in culture, structures and practices as an answer to persistent problems. Following transitions' thinking, we will draw process-oriented propositions for sustainability transitions that give rise to research propositions for governance of transitions (Section 4).

\section{Sustainability and sustainable development: Existing propositions}

Since the late 1980's, many countries have committed themselves to sustainable development but are struggling with how to do this. Following the Brundtland report Our Common Future (WCED, 1987), sustainable development came to be defined as redirection of social development in ways that combine prosperity, environmental protection with social cohesion. In this report, sustainable development was defined as a development that meets the needs of the current generation, without compromising the needs of future generations (WCED, 1987). This definition is normative since future generations should have the same possibilities, subjective since it requires an assessment of what these future needs are, and also ambiguous since these future needs are determined by cultural, ecological and economic developments that can be weighted in more than one way (Martens and Rotmans, 2002; UN, 1997).

At the international level there is a consensus on the need for sustainable development and key areas in which the next decade significant progress needs to be made: poverty, hunger, health, education, life expectancy, environmental sustainability and global partnerships (UN, 2005). The approach to sustainable development adopted by the $\mathrm{UN}$ is to realize overall consensus while allowing for a variation of strategies and solutions to be chosen by individual countries, regions and actors at different levels (UN, 2005). This means that in practice different countries have taken up different strategies to cope with the challenge of achieving sustainable development. A lot of countries opted for sustainability councils and the development of sustainability indicators (see Mulder, 2006, pp.148-165). In this context, sustainable development has been represented as the intersection of economic, social and environmental agendas and the need to integrate (predominantly) environmental concerns into regular policies.

We can derive some basic characteristics that are attributed to the concept of sustainable development that occur in almost all definitions and scientific writings (Rotmans, 1994; Rotmans et.al., 2001). The first is that sustainability is intergenerational. This means that a long-time horizon, at least one or two generations (25-50 years), has to be considered. The second characteristic is the importance of scale. Sustainability occurs at different levels; local or regional sustainability does not necessarily mean national or global sustainability and vice versa. Sustainability analysis thus requires a multitude of scale levels. The third common characteristic is that sustainability related to multiple domains. Sustainability encompasses a certain context-

\footnotetext{
${ }^{1}$ We perceive governance as meta-level pattern of societal interactions (intended and unintended) or as Kooiman (1993, p.2) notes, governance to be interactive as "the pattern that emerge from the governing activities of social, political and administrative actors" that "focuses on the interactions taking place between governing actors within social-political situations." (Kooiman, 2003, p.7).
} 
specific balance between ecological, economic and socio-cultural values and stakes (Kates et. al., 2001; Pezzoli, 1997).

Sustainable development is therefore a normative orientation that provides a frame of reference to discuss and direct differences in perception, ambition and understanding between actors in light of desired changes in society. After the initial optimism during the 1990's about win-win opportunities, it is increasingly understood that there are tradeoffs between different values and interests in any type of development (at least in the short term) and that each development tosses up new problems for society. The rationale behind these is that alternatives for development can only be called sustainable when they are (co-)developed, implemented and formulated by societal actors (Clark, 2003).

What we suggest is that sustainable development should be considered as a continuous process in which societal values and interests are represented, negotiated and balanced. At the same time, new alternatives and visions need to be explored and experimented with. Sustainable development is a multi-dimensional, dynamic and plural concept that neither can be translated into the narrow terms of static optimization nor is conducive to strategies based on direct control (Loorbach, 2004; Rammel et. al., 2004). This is a distinctive characteristic of sustainable development as a new type of development process vis-à-vis economic development: the goal of sustainability exists but its target level changes over time due to its redefinition by every generation (Mulder, 2006, p.74). As Meadowcroft (1997, p.37) phrases this perspective: "Each generation must take up the challenge anew, determining in what directions their development objectives lie, what constitutes the boundaries of the environmentally possible and the environmentally desirable, and what their understanding of the requirements of social justice is".

Arguably, sustainable development as a broad notion of an integrative and balanced, yet flexible societal development should be used as guiding principle for future-oriented actions. This means that the challenge of sustainable development can be formulated in terms of the quality and the characteristics of a continuous governance process that enables representation of various perspectives, values and interest and creates space for experimentation, innovation and learning. Understanding which dynamics play what type of role and how they can be anticipated, adapted to and influenced is the central aim of the transitions approach,

\section{Transitions approach for sustainability}

The focus of the current paper is on sustainability transitions or transitions to sustainability that concern the continuous process of fundamental change that reorient and restructure a societal system towards a sustainable system state that satisfies sustainability values. In line with this and as already indicated in the introduction, the transitions approach implies an integrative concept of sustainability, which is capable of incorporating multiple domains, levels of scale and spans a long-term.

\subsection{Foundations of transitions thinking}

In the early 1990s complex systems theory was introduced, focusing on the co-evolutionary development of systems. The establishment of the Santa Fé institute in New Mexico in the US in 1984 functioned as incubator for a new research movement, which laid the basis for complex adaptive systems theory (Holland, 1995; Kauffman, 1995). Although the theory is far from mature, it has attracted a great deal of attention and has many applications in diverse research fields: in biology (Kauffman, 1995), economics (Arthur et.al., 1997), ecology (Gunderson and Holling, 2002) and public administration (Kickert, 1991; Teisman, 1992). The basic idea is that complex interactions between different elements can be understood in a systemic sense: through

Paper for: Sustainable Development: A challenge for European research 
their interaction, elements within a system co-evolve with each-other and with their environment, new structures and novelties emerge and new configurations appear through self-organization.

The basic mechanisms that drive change in complex adaptive systems are co-evolution, emergence and self-organization. Societal systems can be considered as complex adaptive systems. Societal sectors consist of numerous interlinked elements (e.g. actors and institutions), there is a high degree of uncertainty about their interactions and feedback and they have an open and nested character in terms of different levels of organisation. From this perspective, typical complex system behaviour can be recognized, as for example emerging structures, co-evolving (policy) domains and self-organizing processes can be observed. One of the possible patterns distinguished is that of transition: a system in a relatively stable equilibrium is (suddenly) going into a phase of rapid change through a process in which self-organisation and co-evolution play an important role before a new equilibrium is found.

\subsection{Transitions perspective on systems innovation}

History has witnessed numerous transitions in economy, agriculture, mobility, and energy, but also in areas such as education, health care, and social structure (Geels, 2004; Rotmans et. al, 2001). Transitions are processes of 'degradation' and 'breakdown' as well as of 'build up' and 'innovation' (Gunderson and Holling, 2002) or of 'creative destruction' (Schumpeter, 1934) of societal structures. The central assumption is that societal structures go through long periods of relative stability and optimization that are followed by relatively short periods of structural change. These changes can be analyzed in terms of multi-level (distinguishing between dominant structures/regimes, upcoming innovations/niches and landscape development (Geels, 2004)) and multi-phase frameworks (in terms of predevelopment, take-off, acceleration and stabilization (Rotmans, 1994)).

\subsection{Transitions perspective on systems' sustainability}

Historically, transitions have been primarily driven by changes in social subsystems that initiated large-scale changes such as demographic growth, technological innovation or economic expansion. In a sense, these historical transitions (such as those part of the industrialization era, the post-war emergence of mobility, intensive agriculture or fossil energy systems), were also partly driven by the promise of solving societal problems such as poverty, inequality, education and so on. Such transitions however produced, in dealing with certain issues, their own problems in turn. While individuals might now have availability of cheap energy and mobility, it has coproduced for example pollution, resources' exploitation and congestion. In that sense, the transitions leading to our current modern society have had as side-effect the current environmental problems. The challenge in dealing with modern problems is to find new ways in dealing with them in a more anticipatory and exploratory manner.

The transition perspective is that while complex processes of change are occurring, we need to try to better understand their dynamics and try to influence their pace and direction. Combined with the basic notion that sustainability is ambiguous, uncertain and contested, this means that the only way to 'enable' sustainable development is through process conditions under which sustainability is discussed, negotiated and explored in light of the major changes that are undoubtedly necessary.

A process-philosophy of sustainable development seems very useful in order to accommodate concrete action and implementation and allow for plurality in both actor's and objectives and for flexibility of the outcome. Linked to the need to achieve fundamental change implies that to accommodate and facilitate frontrunners in society to work collectively to transform social 
systems towards sustainability in the long-term, but to compete over best solutions and conflicting values on the short-term. Such an approach raises discussion issues about democratic legitimacy, accountability and control (Hendriks and Grin, 2007; Shove and Walker, 2007), but at the same time questions the legitimacy of the existing dominant institutions since they are not able to include uncertain future processes and/or to create the level of social innovation needed for transitions.

Dominant (policy and research) approaches predominantly seek to improve existing systems, leading to gradual improvement. Opposing this, transitions' thinking suggests that a sustainable development process requires a fundamental shift of a societal system. Instead of incremental changes that aim at preserving existing functioning, transition thinking focuses on radical changes or "transformation of both (...) systems and social structures and practices" (after Meadowcroft, 1997, p.430). It is concluded that apart from a co-evolving target of sustainability that a society needs to form, process conditions ${ }^{2}$ are essential in creating space and paving the ground for a societal transition to sustainability.

\section{Governance for sustainability transitions}

Sustainable development as a societal objective is a continuous intergenerational, multi-scale (global and local) and multi-domain process of seeking a balance between social, economic, ecological and cultural values. As such, sustainable development requires a governance mode that promotes those societal processes that guard sustainability values. Transitions' thinking offers a ground for process-oriented propositions for a transition to sustainability.

\subsection{Starting process-propositions of sustainability transitions}

The transition approach focuses on understanding societal dynamics that underlie transitions. The knowledge of those dynamics is translated into process-oriented propositions that comprise the headlines of transitions' approach (see Loorbach, 2007).

Proposition 1: Sustainability transitions are long-term processes of fundamental societal change that incorporate processes of societal, ecological, economic, cultural and technological evolution.

Proposition 2: Enabling societal processes of change (transitions) implies an integrated understanding of the dynamics of change and deliberate and reflexive strategies so as to allow for self-orientation of society towards a sustainable development pathway.

Proposition 3: Innovation and sustainable development are interlinked: to develop sustainably means to continuously innovate and redefine existing culture, structures and practices in an evolutionary manner. More specifically, a focus on sustainability could trigger innovations that comply with sustainability values as well as that these innovations can be the stimuli for initiation of multi-domain processes for societal transitions to sustainability.

Proposition 4: Sustainability transitions are continuous open-ended processes of societal innovation. Governance for sustainability transitions has thus to secure sustainability values such as long-term orientation and intergenerational justice.

\footnotetext{
2 Process-oriented conditions or process-oriented propositions relate to the process design towards restructuring the societal system. Process-oriented propositions are not concerned with the definition of targets, or goals but with the design or the framing of the actions that will take place over the course of a transition.
}

Paper for: Sustainable Development: A challenge for European research 


\subsection{Towards governance for sustainability transitions: Transition guidelines and research questions}

Research on transition dynamics and transition management resulted in a number of starting transition process guidelines that are related to the above propositions. Given the complexity of phenomena as societal transitions, the below listed process guidelines are not set in stone but can and will evolve due to scientific debate and practical implementation. This approach is fundamentally different from a (more) descriptive and analytical scientific approach that would primarily focus on understanding these processes and describing them. The questions formulated below are in line with this based upon recent theoretical debates and empirical insights around transition management. An additional remark is that future research on sustainable development will require a focus on new modes of governance for promoting sustainability transitions.

Proposition 1: Sustainability transitions are long-term processes of fundamental and radical societal change that incorporate processes of societal, ecological, economic, cultural and technological evolution.

Transition process-guidelines:

(a) The dynamics of the system create feasible and non-feasible means for governance. This implies that substance and process are inseparable. Process management on its own is not sufficient - insight into how the system works is an essential precondition for effective management. Systems-thinking (in terms of more than one domain (multidomain) and different actors (multi-actor) at different scale levels (multi-level); analyzing how developments in one domain or level interact with developments in other domains or levels) is necessary to be able to take into account such possible means and leavers for intervention.

(b) Learning-by-doing and doing-by-learning. Social learning is a pivotal aspect of societal transition processes, aimed at 'reframing', changing the perspective of actors involved. Social learning as the combined outcome of learning-by-doing and doing-bylearning actions stimulates the development of visions, pathways and experiments that form a new context as well as pave the ground for the reorientation of the societal system.

Research questions:

- Which are the prevailing patterns of societal transitions in the form of multi-domain processes of change/evolution?

- Can we distinguish different types of transitions related to sustainability issues and what does that mean in terms of societal dynamics?

- Is it possible to understand ongoing transitions in which we all are part and if so, are we able to influence these?

Proposition 2: Enabling societal processes of change (transitions) implies an integrated understanding of the dynamics of change and deliberate and reflexive strategies so as to allow for self-orientation of society towards a sustainable development pathway.

Transition process-guidelines:

(a) Radical change in incremental steps. Radical, structural change is needed to erode the existing structure of a system and ultimately dismantle it. Immediate radical change, however, would lead to maximal resistance from the deep structure, that cannot adjust to a too fast, radical change. Abrupt forcing of the system would disrupt the system and would create a backlash in the system because of its resilience. Incremental change allows the system to adjust to the new circumstances and to build up new structures that align to the new configuration. Radical change in incremental steps thus implies that the system heads for a new direction towards new attractors, but in small steps.

Paper for: Sustainable Development: A challenge for European research 
(b) Objectives should be flexible and adjustable at the system level. The complexity of the system is at odds with the formulation of specific objectives. With flexible evolving objectives one is in a better position to react to changes from inside and outside the system. While being directed the structure and order of the system are also changing, and so the objectives set should change too.

Research questions:

- How can we better understand complex evolutions in society to make better use of complex system dynamics?

- Which are the means for governance that can deliberately promote societal transitions while allowing self-organization and self-orientation of the societal system?

\section{Proposition 3: Innovation and sustainable development are interlinked.}

Transition process-guidelines:

(a) Creating space for niches in transition arenas and transition experiments. A niche is a new structure, a small core of agents that emerges within the system and is seen as the incumbent for innovation. An emergent structure is formed around niches to stimulate the further development of these niches and the emergence of niche-regimes.

(b) A focus on frontrunners. In this context we mean with frontrunners agents with peculiar competencies and qualities: creative minds, strategists and visionaries. Frontrunners are able to generate dissipative structures in complex systems and are active at different levels and domains.

(c) Guided variation and selection. Diversity is required to avoid rigidity within the system. Rigidity here means reduced diversity due to selection mechanisms which means that the system cannot respond flexibly to changes in its environment. Rather than selecting innovative options in a too early stage options are kept open in order to learn about the pros and cons of available options before making a selection. Collective choices are made "along the way" on the basis of learning experiences at different levels.

Research questions:

- Which modes of governance can promote innovation while securing sustainability values in multiple domains?

- Which are means for governance that can create space for innovation that complies with sustainability values apart from regulation and institutionalization of innovation systems?

- Which are means for governance that can anticipate multiple visions and values of sustainability while facilitating the adaptation of innovation?

Proposition 4: Sustainability transition is a continuous open-ended process of societal innovation. Governance for sustainability transitions has thus to secure sustainability values such as long-term orientation and intergenerational justice

Transition process-guidelines:

(a) Long-term thinking as a framework for shaping short-term policy in the context of persistent societal problems. Processes of back- and fore-casting: the setting of shortterm goals based on long-term goals and the reflection on future developments through the use of scenarios.

(b) Anticipation and adaptation. Anticipating future trends and developments, taking account of weak signals and seeds of change acting as the harbingers of the future, is a key element of a pro-active, long-term strategy as transition management. This future

Paper for: Sustainable Development: A challenge for European research 
orientation is accompanied by a strategy of adaptation, which means adjusting while the structure of the system is changing.

\section{Research questions:}

- How can governance deal with the tension between promoting continuous innovation while at the same time needing to offer social stability and institutional structure?

- Which are the means for governance that incorporate long-term orientation and its uncertainties?

- Which are the means for governance that ensure reflexivity and adaptability in face of long-term processes of transitions to sustainability?

\section{Reflection and discussion}

This paper sketched the outlines of the transition perspective on sustainability and the consequences that are drawn from this perspective in terms of the contours of governance for sustainability transitions. The transition approach and transition management focus on understanding and promoting societal processes and thus on integrating theoretical with empirical knowledge. We have argued that a process-based approach to sustainability and the integration with the transition perspective has implications for the role of research and knowledge: transitions are uncertain processes that cannot be predicted or fully analyzed. Hence, we argue that certain key patterns and dynamics can be understood and used to reflect upon the possibilities for accelerating and orienting these transitions.

The research needed in understanding and in dealing with transitions is of an inter- and transdisciplinary nature. Consequently, the research questions formulated cannot be answered in a traditional way: the empirical object (transitions) is continuously on the move. Transition research poses a challenge to the scientific community at large: the complex sustainability problems require the involvement of scientists who step over the boundaries of their scientific disciplines so as to develop new insights, to transfer new knowledge and in general to become part of the collective societal search process we call sustainable development.

\section{References}

Arthur, W. B., Durlauf, S. N., and Lane, D. A. (1997). The economy as an evolving complex system. Reading, MA: Addison-Weasly.

Bolin, B., W. Clark, R. Corell, N. Dickson, S. Faucheux, G. Gallopín, A. Gruebler, M. Hall, B. Huntley, J. Jäger, C. Jaeger, N. Jodha, R. Kasperson, R. Kates, I. Lowe, A. Mabogunje, P. Matson, J. McCarthy, H. Mooney, B. Moore, T. O'Riordan, J. Schellnhuber, U. Svedin. (2000). Core Questions of Science and Technology for Sustainability.

Clark, W. C. (2003). Sustainability, energy use and public participation. In B. Kasemir, J. Jager, C. Jaeger \& M. Gardner (Eds.), Public Participation in Sustainability Science. Cambridge: Cambridge University Press.

Flyvbjerg, B. (2001). Making Social Science Matter. Why social inquiry fails and how it can succeed again. Cambridge: Cambridge University Press.

Geels, F. (2004). Sectoral systems of innovation to socio-technical systems; Insights about dynamics and change from sociology and institutional theory. Research Policy, 33, 897920.

Gunderson, L. H., and Holling, C. S. (2002). Understanding transformations in human and natural systems. Washington: Island Press.

Hendriks, C. M., and Grin, J. (2007). Contextualising reflexive governance: the politics of Dutch transitions to sustainability. Journal of Environmental Policy \& Planning, 9(3-4), 333350 . 
Holland, J. H. (1995). Hidden Order: How Adaptation Builds Complexity. Cambridge, Massachusetts: Helix books / Perseus books.

Jansen, L. (2003). The challenge of Sustainable Development. Journal of Cleaner Production, 11, 231-245.

Kates, R. W., Clark, W. C., Corell, R., Hall, J. M., Jaeger, C. C., Lowe, I., et al. (2001). Environment and development - Sustainability science. Science, 292(5517), 641-642.

Kauffman, S. (1995). At home in the universe: the search for laws of complexity. Oxford: Oxford University Press.

Kickert, W. J. M. (1991). Complexiteit, zelfsturing en dynamiek. Over management van complexe netwerken bij de overheid. Unpublished Oratie, Erasmus Universiteit, Rotterdam.

Kooiman, J., (Ed.), (1993), Modern governance, Sage, Newbury Park, CA.

Kooiman, J., (2003), Governing as governance, Sage, Newbury Park, CA.

Loorbach, D. (2004). Governance and transitions: a multi-level policy-framework based on complex systems thinking. Paper presented at the Conference on Human Dimensions of Global Environmental Change, Berlin.

Loorbach, D. (2007). Transition management: new mode of governance for sustainable development. Utrecht: International Books.

Martens, P., and Rotmans, J. (2002). Transition in a globalizing world. Lisse: Swets \& Zeitlinger B.V.

Meadowcroft, J. (1997). Planning for sustainable development: insights from the literatures of political science. European Journal of Political Research, 31, 427-454.

Meadowcroft, J. (2000). Sustainable Development: a New(ish) Idea for a New Century? Political Studies, 48, 370-387.

Mulder, K., (Ed.), (2006), Sustainable development for engineers, A handbook and resource guide, Greenleaf Publishing.

Pezzoli, K. (1997). Sustainable Development: a transdisciplinary overview of the literature. Journal of Environmental Planning and Management, 40(5), 549-574.

Rammel, C., Hinterberger, F., and Bechtold, U. (2004). Governing Sustainable Development (Working Paper No. No. 1). Vienna: GoSD.

Rotmans, J. (1994). Transitions on the move; Global Dynamics and Sustainable Development.Bilthoven, The Netherlands: Rijksinstituut voor Volksgezondheid en Milieu (RIVM).

Rotmans, J., Kemp, R., and Van Asselt, M. (2001). More evolution than revolution: Transition management in public policy. Foresight, 03(01), 17.

Shove, E. and Walker, G., (2007), 'CAUTION! Transitions ahead: Politics, practice and sustainable transition management', Environment and Planning A, 39(4), 763-770

Schumpeter, J. A. (1934). The Theory of Economic Development. Cambridge, MA: Harvard University Press.

Scott, W., \& Gough, S. (Eds.). (2004). Key issues in sustainable development and learning: a critical review. London: Routledge.

Teisman, G. R. (1992). Complexe besluitvorming, een pluricentrisch perspectief. 's Gravenhage: Elsevier.

UN. (1997). Global Change and Sustainable Development: Critical Trends. New York: United Nations, Department for Policy Coordination and Sustainable Development.

UN. (2005). The Millennium Development Goals report. New York: United Nations.

WCED. (1987). Our Common Future. Oxford: University Press.

Paper for: Sustainable Development: A challenge for European research 